\title{
Seismic hazard at the Rosebery mine
}

\author{
C Knobben MMG Limited, Australia
}

\begin{abstract}
Various tools are available to geotechnical engineers in mines to assess the current seismic hazard, and changes to the seismic hazard over time. Although detailed analysis of seismicity is generally conducted by geotechnical engineers, a simplified approach needs to be applied for the reporting and communicating of the change in seismic hazard over time to management. As a result, management can make informed decisions on mining approaches, taking into consideration a seismic hazard that is relatable and applicable to the mining environment. A process for assessing the seismic hazard has been developed using a modification of work conducted on the seismic hazard scale in Western Australian mines, with relation to specific time periods, allowing seismic hazard to be quantified over time.
\end{abstract}

Keywords: seismicity, hazard, management

\section{Introduction}

Rosebery mine, owned and operated by Minerals and Metals Group Limited (MMG), is a hard rock mine located on the west coast of Tasmania with the current mining at approximately 1,800 $\mathrm{m}$ below the surface (Figure 1). As a result of high in situ stresses in relation to the rock mass strength, mining-induced seismicity has progressively become a hazard to the safety and economic operation of the mine.

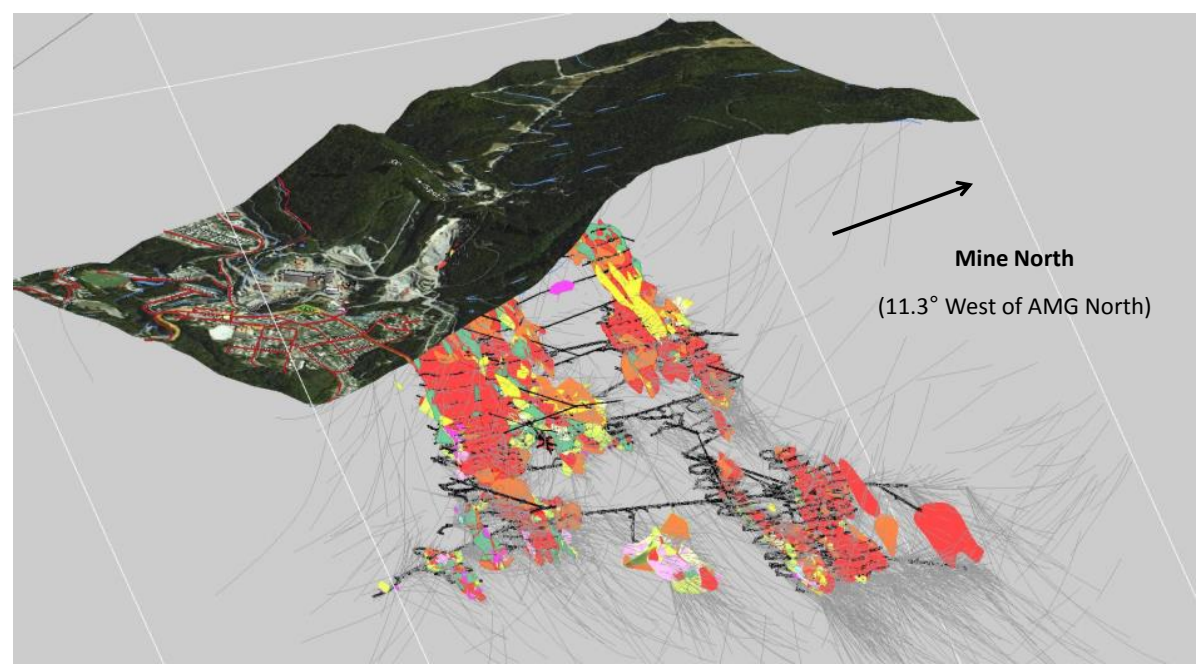

Figure 1 Perspective view of the Rosebery township and Mount Black to the north, with historical underground mining operations and drillhole traces (looking down and towards the northwest)

As mining progressed to greater depths at the Rosebery mine, seismicity became more prevalent, leading to the installation of a seismic monitoring system in 2006. Recorded seismic related falls of ground occurred in 2012 and 2014. Each fall of ground increased the focus and reliance on both seismic monitoring and dynamic ground support practices.

The safety management of mining-induced seismicity has increasingly become an important aspect of mining in deep, hard rock Australian mines, especially with the introduction of dedicated seismic systems in the 1990s (Hills 2013). Mines have identified that seismicity can result in significant impacts to both the safety and productivity of the operation. This paper discusses mine seismic hazards from identification and understanding to management in line with safety and production goals of the mine. 


\section{$2 \quad$ Setting and ground behaviour}

The Rosebery mine has been operating at full-scale production since 1936 and was acquired by MMG in 2009. Small bench stoping is the primary source of ore extraction of the mine with common stopes $20 \mathrm{~m}$ along strike, $25 \mathrm{~m}$ in height and 5-20 $\mathrm{m}$ in width (Figure 1).

Rock mass conditions at the Rosebery mine are generally good with rock quality designation (RQD) values varying between 70 and $100 \%$. The rock mass contains a dominant regional foliation with three main joint sets. Q values for the rock mass vary from 3-10, mostly as a result of high in situ stress conditions in relation to the rock mass strength. Damage to the rock mass, as a result of stress change, presents itself as shearing along foliation predominantly in the oredrives and other strike parallel headings (within proximity to the lenses) resulting in excavation instability. Overbreak in stopes is generally assisted with unravelling of the foliation causing arching of the hanging wall or unclamping of structures striking subparallel to foliation that controls hanging wall performance. Seismic response has been observed during stope failures and commonly around stope blasting times.

\section{Seismic system layout}

The Rosebery mine started monitoring seismicity in 2006, with an Engineering Seismology Group (ESG) seismic system, as a result of heightened awareness of seismic related hazards in the mining industry. In 2013 , as a result of a seismic-induced fall of ground at the mine, the seismic system was broadened. During this time, the system was also replaced with an Institute of Mine Seismology (IMS) system.

At the current time, the seismic monitoring system at the Rosebery mine consists of 26 geophones (15 uniaxial and 11 triaxial) located throughout the working areas of the mine (Figure 2). The system has been designed to record events greater than a local magnitude of $M_{L}-1.0$ (approximate Richter magnitude of -3.0 based on site-specific calibration). The seismic system provides real-time data transfer via an underground fibre optic network through to servers on the surface.

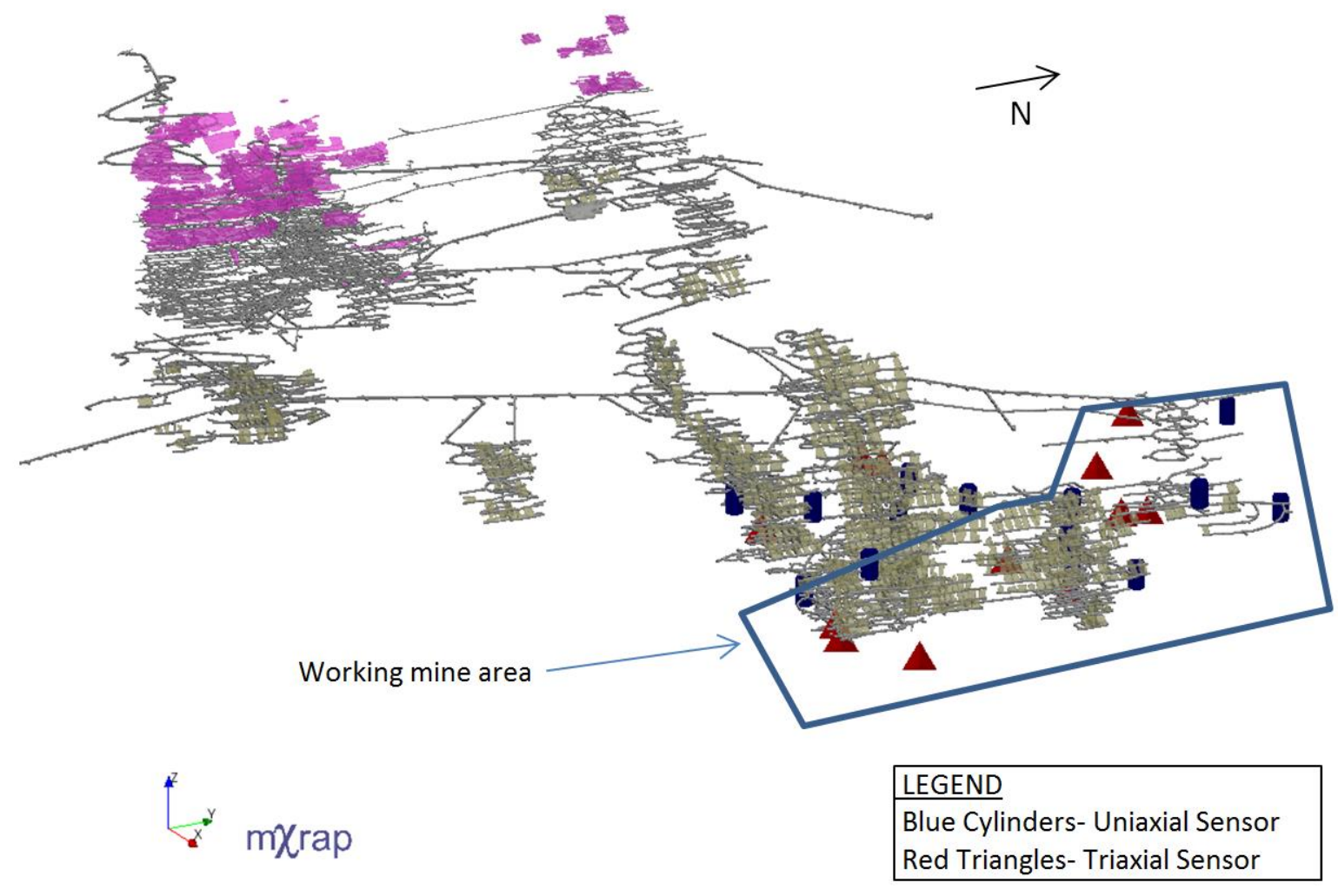

Figure 2 The Rosebery mine seismic system layout, 2016 


\section{$4 \quad$ Current seismic risk management process}

Over time, changes in mining sequences, depth and geology led to changes in the seismic hazard at the mine. The database of seismic events has been critical in assisting with analysis of these changes and the affect on managing and understanding the seismic risk at the mine. Seismic monitoring and analsyis has resulted in the change to seismic risk management plans in an attempt at controlling the seismic hazard.

Management of seismic risks at the Rosebery mine has the primary purpose of ensuring the safety of personnel in the underground environment. The secondary purpose of the system is for consideration to the mine design and operational aspects of the mine.

Methods used in assessing the seismic risk at the Rosebery mine include:

- Post firing events decay.

- Spatial plotting of events.

- Frequency-magnitude analysis.

- Apparent stress/time history.

- Focal mechanisms.

- Estimation of peak particle velocity.

An understanding of these methods requires a lot of training and knowledge of seismicity, which is generally provided by the geotechnical department. The challenge that geotechnical engineers face is how to convert this knowledge and analysis into meaningful information that management can understand and consider in decision-making processes.

Methods used in communicating seismic management at the Rosebery mine include:

- Daily seismic reporting and analysis.

- Stope firing seismic re-entry analysis.

- Back analysis of seismicity.

- Seismic hazard analysis.

- Monthly seismic report, which considers the previous month seismicity and sources, and then attempts to assess upcoming production activities and recommended controls considering the seismic response.

Seismic hazard analysis provides a large part in seismic risk management as it creates a tool that can be understood by technical and operational departments and management.

\section{$5 \quad$ A scale for seismic hazard}

To ensure that mine seismicity is appropriately understood, consistently assessed, and controlled by mine management, it is important that hazards are communicated in a relatable manner. Hazard scales are common practice in mines and management as a result of legislation (Standards Australia 2009) and are generally used to identify hazards by understanding the consequence and likelihood of an event happening (risk matrix). By using the measure of 'likelihood' and 'consequence', in the context of mine seismicity, a simple hazard scale has been adopted from research published by Hudyma and Potvin (2004). This process detemines a seismic hazard scale, using the number of seismic events of specific magnitudes (likelihood) and the seismic magnitude (consequence), (Table 1). 
Table 1 Seismic Hazard Scale (Hudyma \& Potvin 2004)

\begin{tabular}{|c|c|c|c|c|c|c|}
\hline \multicolumn{7}{|c|}{ Mine seismicity frequency per day } \\
\hline \multirow{2}{*}{\multicolumn{2}{|c|}{$\begin{array}{l}\text { Qualitative } \\
\text { description } \\
\text { Approx. Richter } \\
\text { magnitude }\end{array}$}} & \multirow{2}{*}{$\begin{array}{l}\text { Felt locally } \\
M_{L}>=-2\end{array}$} & \multirow{2}{*}{$\begin{array}{l}\text { Felt in parts of a mine } \\
\text { like a secondary blast } \\
\qquad \begin{array}{c}M_{L}>=-1 \\
\text { Seismic hazard }\end{array}\end{array}$} & $\begin{array}{l}\text { Often felt on surface, or } \\
\text { like a development blast }\end{array}$ & Felt like a production blast & \multirow[t]{2}{*}{$\begin{array}{l}\text { Detected by regional } \\
\text { earthquake network }\end{array}$} \\
\hline & & & & $\begin{array}{l}\qquad M_{L}>=0 \\
\text { :ale and qualitative descrip }\end{array}$ & $M_{L}>=+1$ & \\
\hline \multirow{2}{*}{-2} & \multirow{2}{*}{ Nil } & $>0.001$ & 0 & 0 & 0 & 0 \\
\hline & & (once every few years) & (has never occurred) & (has never occurred) & (has never occurred) & (has never occurred) \\
\hline \multirow{2}{*}{-1} & \multirow{2}{*}{ Very low } & $>0.01$ & $>0.001$ & 0 & 0 & 0 \\
\hline & & (a few times per year) & (once every few years) & (has never occurred) & (has never occurred) & (has never occurred) \\
\hline \multirow{2}{*}{0} & \multirow{2}{*}{ Low } & $>0.1$ & $>0.01$ & $>0.001$ & 0 & 0 \\
\hline & & (at least weekly) & (a few times per year) & (once every few years) & (has never occurred) & (has never occurred) \\
\hline \multirow{2}{*}{0.5} & \multirow{2}{*}{$\begin{array}{l}\text { Low to } \\
\text { moderate }\end{array}$} & $>0.3$ & $>0.03$ & $>0.003$ & $<0.001$ & 0 \\
\hline & & (a few times per week) & (monthly) & (yearly) & (may have happened once) & (has never occurred) \\
\hline \multirow{2}{*}{1} & \multirow{2}{*}{ Moderate } & $>1$ & $>0.1$ & $>0.01$ & $>0.001$ & 0 \\
\hline & & (at least daily) & (at least weekly) & (a few times a year) & (once every few years) & (has never occurred) \\
\hline \multirow{2}{*}{1.5} & \multirow{2}{*}{$\begin{array}{l}\text { Moderate } \\
\text { to high }\end{array}$} & $>3$ & $>0.3$ & $>0.03$ & $>0.003$ & $<0.001$ \\
\hline & & (a few a day) & (a few times a week) & (monthly) & (yearly) & (may have happened once) \\
\hline \multirow{2}{*}{2} & \multirow{2}{*}{ High } & $>10$ & $>1$ & $>0.1$ & $>0.01$ & $>0.001$ \\
\hline & & (more than 10 a day) & (at least daily) & (at least weekly) & (a few times a year) & (once every few years) \\
\hline \multirow{2}{*}{2.5} & \multirow{2}{*}{$\begin{array}{l}\text { High to } \\
\text { very high }\end{array}$} & $>30$ & $>3$ & $>0.3$ & $>0.03$ & $>0.003$ \\
\hline & & (more than 30 a day) & (a few a day) & (a few times a week) & (monthly) & (yearly) \\
\hline \multirow{2}{*}{3} & \multirow{2}{*}{ Very high } & $>100$ & $>10$ & $>1$ & $>0.1$ & $>0.01$ \\
\hline & & (more than 100 a day) & (more than 10 a day) & (at least daily) & (at least weekly) & (a few times a year) \\
\hline \multirow{2}{*}{3.5} & \multirow{2}{*}{$\begin{array}{l}\text { Very high } \\
\text { to } \\
\text { extreme }\end{array}$} & $>300$ & $>30$ & $>3$ & $>0.3$ & $>0.03$ \\
\hline & & (more than 300 a day) & (more than 30 a day) & (a few a day) & (a few times a week) & (monthly) \\
\hline \multirow{2}{*}{4} & \multirow{2}{*}{ Extreme } & $>1,000$ & $>100$ & $>10$ & $>1$ & $>0.1$ \\
\hline & & (more than 1,000 a day) & (more than 100 a day) & (more than 10 per day) & (at least daily) & (at least weekly) \\
\hline
\end{tabular}

The use of the seismic hazard scale, as outlined by Hudyma and Potvin (2004), forms a basis for the comparison of seismicity between mines. Using data from a seismic system, or a concise rocknoise database, most mines are able to identify where conditions locate on this scale. It is important to note that the seismic event size is based on the Richter magnitude scale and that a conversion from a local magnitude scale will likely be required at most mine sites.

\section{An adaption of the seismic hazard scale}

The seismic hazard scale assumes that seismicity at the mine follows a Gutenburg-Richter relation with a b-value of 1 . As a result, a calculation of the seismic hazard is proposed to determine where in the seismic hazard range the mine locates (Equation (1)).

$$
\begin{aligned}
& \text { Seismic Hazard }=\left(\frac{\left(\sum M_{R}>-2\right)}{P}\right)+\left(\left(\frac{\left(\sum M_{R}>-1\right)}{P}\right) \times 10\right)+\left(\left(\frac{\left(\sum M_{R}>0\right)}{P}\right) \times 100\right)+\left(\left(\frac{\left(\sum M_{R}>1\right)}{P}\right) \times 1000\right) \\
& +\left(\left(\frac{\left(\sum M_{R}>2\right)}{P}\right) \times 10000\right)
\end{aligned}
$$

where:

$$
\begin{array}{ll}
\sum M_{R}>\beta & =\text { sum of events greater than a magnitude } \beta \text { in a certain period. } \\
M_{R} & =\text { Richter magnitude. } \\
P & =\text { Period of time hazard is calculated over. }
\end{array}
$$

By applying this formula, using values from the seismic hazard scale, the upper limits of the hazard categories can be obtained (Figure 3). For example, for the upper limit of the 'very high to extreme hazard' category, the following calculation is made:

$$
\text { Seismic Hazard }=(1000)+(100 \times 10)+(10 \times 100)+(1 \times 1000)+(0.1 \times 10000)=5000
$$




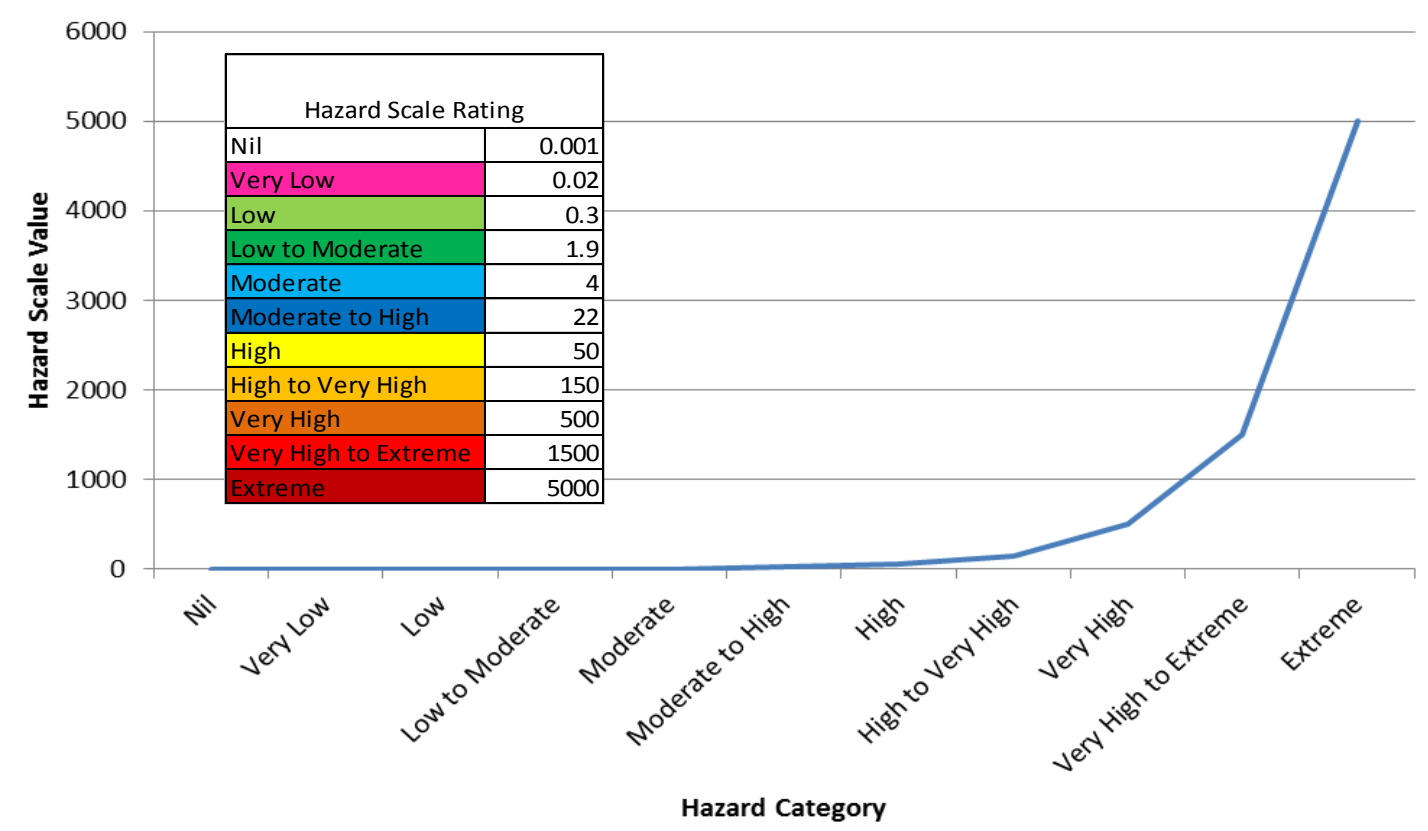

Figure 3 Seismic hazard scale and rating system

The seismic hazard scale is a useful tool for assessing the seismic hazard of the mine at the current time with current mining methods, but does not indicate how the seismic hazard changes over time and throughout different areas of the mine.

By adapting the use of the seismic hazard scale as outlined by Hudyma and Potvin (2004), the scale can be applied to a mine as a whole but also to different areas of the mine, which have dissimilar seismic signatures or mining areas that have been determined to not seismically influence other areas. Examples of this may include:

- Areas with different seismic mechanisms (structurally/stress related).

- Areas that are separated by significant distance where seismic energy is not expected to impact another area.

- Areas where mining in one area is not expected to influence seismicity in another (determined from site historical seismic data analysis).

A good understanding of the mine being analysed, as well as an understanding of how mining influences seismicity, is critical to this approach.

By communicating how the seismic hazard varies between mining areas (Figure 4) to management, appropriate controls can be justified and implemented to ensure the seismic risk to mining operations is applied to the right areas at the right times. This may be in the form of post firing re-entry times, changes to ground support design or adaption of mining methods to suit the seismic hazard. 


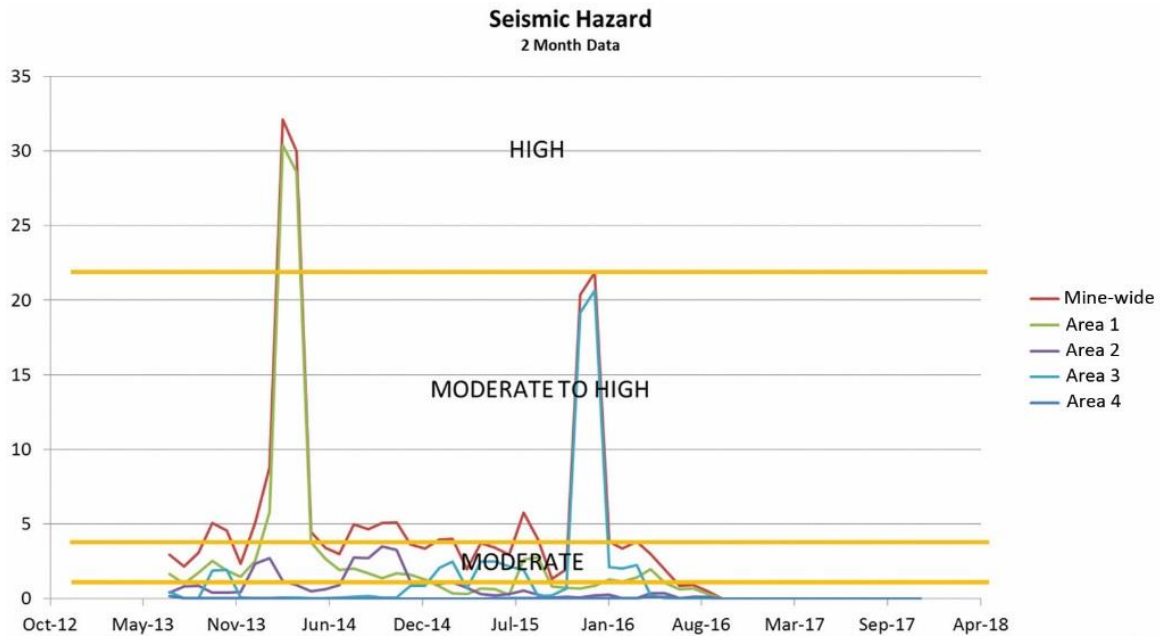

Figure 4 Changes in the seismic hazard for different mining areas ( $\mathrm{Y}$-axis as per Figure 3 )

\section{$7 \quad$ Seismic hazard trends}

Short and long-term analysis of seismic trends allow personnel at mines to understand if current extraction sequences or mining methods are resulting in a change to the seismic hazard. As previously described, this can be done in many ways, many of which are complex, time-consuming and difficult to communicate to people that have limited seismic knowledge.

In order to undertand trends in the seismic hazard, a specific time period needs to be applied for analysis of data. Time periods used in this assessment need to take into consideration the current mining environment being analysed, and must include extraction ratios, mining sequences and excavation sizes. Time periods should also be taken into consideration, whether the analysis is focusing on the short or long-term hazard trends. Short-term analysis may focus on data within the last six months, whereas long-term trends could use data from many years, with longer time periods generally spreading the seismic hazard analysis over an extended period. When analysing the seismic hazard it is a good practice to overlap time periods and conduct analyses on a more frequent basis.

Figure 5 shows an example of the comparison between time periods over which the seismic hazard has been analysed. Two peaks are observed in the short-term data indicating a change in the seismic hazard as a result of larger seismic events, but also shows a drop in seismic hazard within two months, indicating that seismicity reduces shortly after the occurrence of larger events. The long-term data tells a different story, however, with a general steady increase of the seismic hazard followed by a general decrease thereafter.

Seismic Hazard

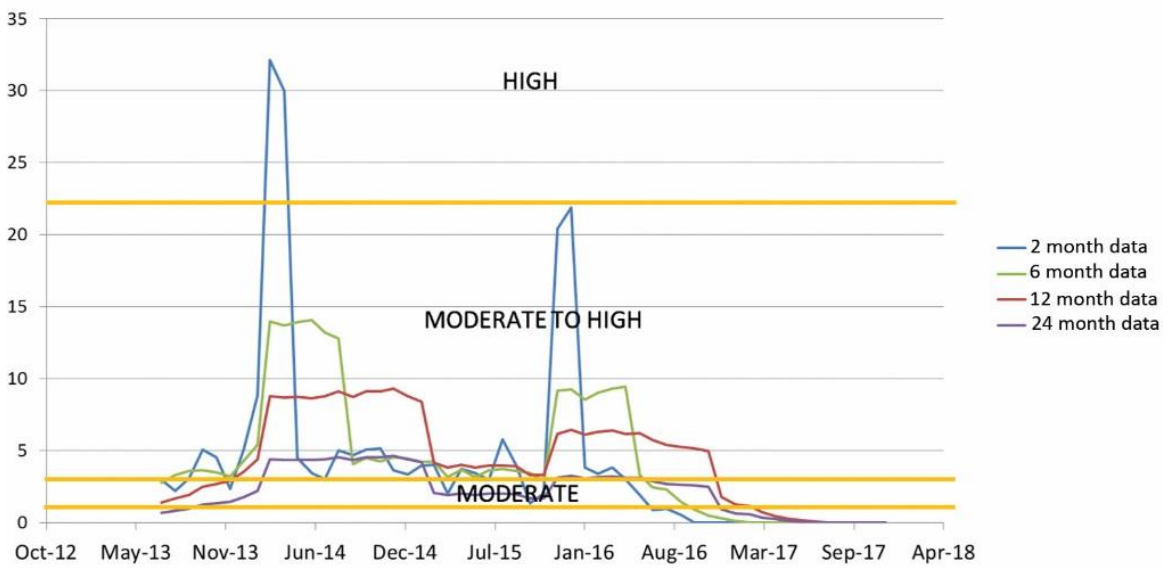

Figure 5 Seismic hazard over different time periods ( $Y$-axis as per Figure 3 ) 
Hazard analysis over the short-term can be communicated using graphical representations to management or analysed to determine if specific mining sequences are resulting in changes to the seismic hazard. Long-term data is applicable for determining if the mining environment is generally resulting in an increase or decrease in the seismic risk.

\section{Discussion}

Relatable communication of seismicity from geotechnical engineers to management (and the entire workforce) is important to ensure seismic hazard is correctly appreciated and, therefore, managed. With the analysis of seismicity, many engineers want to be able to communicate the seismic hazard by attempting to explain changes in seismic energy release, apparent volume or magnitude. Without a detailed understanding of seismicity by management, the message is, at times, hard to get across. Detailed analysis of seismicity is important and regular analysis of mine seismity should be carried out so that geotechnical engineers understand the seismic bahaviour of the mine. It is also just as important that engineers can communicate a simplified and relatable measure of mine seismicity to management, and the workforce, to allow appropriate understanding of the seismic hazard and adequate control of the hazard.

Graphical representations, such as those used in Figures 4 and 5, are good for interpreting the seismic hazard and potential changes. Communication to management can be of the same form, but what does it mean if the seismic hazard is increasing or decreasing? This is where the benefit of the seismic hazard scale is contained, as refering to the matrix it can be illustrated that the likelihood of expecting a damaging seismic event is either increased or decreased. The seismic hazard scale is a great way of communicating seismic hazard as a result of the understanding that an increase in the seismic hazard directly relates to an increase in the likelihood of a large seismic events occuring. For example, between the 'moderate' level and the 'moderate to high' level the risk of a damaging seismic event (assumed to be $M_{\llcorner} 1.0$ ) is three times more likely to occur.

With analysis of the seismic hazard over time, and through different areas of the mine, management are able to better appreciate and implement the correct controls to manage the seismic risk. Controls used at the mine conisder the time frame of exclusion zones following stope firings (Potvin 2009), design of drill and blast practices and consideration into the mine design in relation to mining sequences and risks of leaving rock pillars.

\section{$9 \quad$ Concluding remarks}

The seismic hazard at a mine needs to be understood and managed to meet safety and production goals. Geotechnical engineers need to understand that, as mining progresses, changes to the seismic hazard should be expected. As a result, continual monitoring and analysis of seismicity needs to be conducted to ensure changes to the seismic hazard are within acceptable levels.

Geotechnical engineers also need to understand the limitations of the hazard method and communicate effectively as required.

A method for communicating seismic hazard to management has been developed and has shown to work well at the Rosebery mine. This process not only improves management confidence in decision-making, but ultimately ensures a safer mine for everyone.

\section{References}

Hills, PB 2013, 'Managing mining-induced seismicity', AusIMM Bulletin, August 2013, pp. 54-58.

Hudyma, M \& Potvin, Y 2004, 'Seismic hazard in Western Australian mines', The Journal of The South African Institute of Mining and Metallurgy, June 2004, pp. 265-276.

Potvin, Y 2009, 'Strategies and tactics to control seismic risks in mines', The Journal of The Southern African Institute of Mining and Metallurgy, vol. 109, pp. 177-186.

Standards Australia 2009, ISO/NZS ISO 31000:2009, Risk Management - Principles and Guidelines, Standards Australia, Sydney. 
